\title{
Modeling CA-125 During Neoadjuvant Chemotherapy for Predicting Optimal Cytoreduction and Relapse Risk in Ovarian Cancer
}

\author{
SIMON DUCOULOMBIER ${ }^{1}$, FRANÇOIS GOLFIER $^{1,2}$, OLIVIER COLOMBAN $^{2}$, \\ DAVID BENAYOUN ${ }^{1}$, PIERRE-ADRIEN BOLZE ${ }^{1}$, MICHEL TOD $^{2,3}$ and BENOIT YOU ${ }^{2,3}$ \\ ${ }^{1}$ Service de Chirurgie Oncologique et Gynécologique - Obstétrique, Centre Hospitalier Lyon-Sud, \\ Institut de Cancérologie des Hospices Civils de Lyon (IC-HCL), Lyon, France; \\ ${ }^{2}$ EMR UCBL/HCL 3738, Faculté De Médecine Lyon Sud, Université Lyon 1, Oullins, France; \\ ${ }^{3}$ Centre Hospitalier Lyon Sud, Service d'Oncologie Médicale, CITOHL, Centre Hospitalier Lyon Sud, \\ Institut de Cancérologie des Hospices Civils de Lyon (IC-HCL), Lyon, France
}

\begin{abstract}
Aim: To investigate the prognostic value of modeled CA-125 kinetic parameters regarding surgery outcomes and time to second-line chemotherapy in a population of ovarian cancer patients treated with neoadjuvant chemotherapy followed by interval cytoreduction. Patients and Methods: This retrospective study included consecutive patients with FIGO stage IIIc/IV ovarian cancer treated between 2006 and 2014. We characterized CA-125 kinetics and identified modeled kinetic parameters. Results: Fifty four patients were included. KELIM (modeled CA-125 elimination rate constant) was an independent predictive parameter of optimal cytoreduction $(O R=0.18 ; 95 \% \quad C I=0.04-0.69 ; p=0.02)$. In the optimal cytoreduction population (40 patients, $74.1 \%), E_{50}$ (concentration producing $50 \%$ of the maximum chemotherapy effect) was a significant prognostic parameter regarding time to second-line chemotherapy $(H R=0.38 ; 95 \% C I=0.173-0.854$; $p=0.019)$. Conclusion: We identified CA-125 modeled kinetic parameters during neoadjuvant chemotherapy harboring potential predictive values regarding the likelihood of optimal cytoreduction, along with time to second-line chemotherapy in optimally-cytoreduced patients.
\end{abstract}

Correspondence to: Dr. Benoit You, MD, Ph.D., Centre Hospitalier Lyon-Sud, Centre d'Investigation de Thérapeutiques en Oncologie et Hématologie de Lyon (CITOHL)/Lyon Investigational Center for Treatments in Oncology and Hematology, EMR UCBL/HCL 3738, http://www.pols-phase1.eu/Service d'oncologie d'Oncologie médicaleMédicale, Chemin du Grand Revoyet, 69495 Pierre-Benite, France. Tel: +33 0478864318, Fax: +33 0478864356, e-mail: benoit.you@chu-lyon.fr

Key Words: Epithelial ovarian cancer, neoadjuvant chemotherapy, CA-125 kinetics, mathematical modeling, cytoreduction prediction, second-line chemotherapy.
Epithelial ovarian cancer (EOC) is the seventh most common cancer in the world among women. Moreover it is the eighth cause of cancer-related deaths (1). Sixty to $75 \%$ of patients have advanced disease with peritoneal involvement at diagnosis $(2,3)$, and only $20-25 \%$ can be expected to be long-term survivors.

The standard therapy of advanced epithelial ovarian cancer relies on primary debulking surgery followed by adjuvant chemotherapy when optimal resection is possible (4). Post-operative residual disease is one of the most important prognostic factors regarding survival (5-7). Unfortunately, optimal debulking surgery is not feasible in patients with too extensive involvement of peritoneum and gastro-intestinal structures. The use of NAC (neoadjuvant chemotherapy) before IDS (interval debulking surgery) has been developed to reduce the disease bulk and resections, as well as to select patients with chemosensitive tumors. Based on the data of recent trials suggesting the efficacy of NAC before IDS regarding progression free survival and overall survival $(6,8)$, American Society of Clinical Oncology has recognized this strategy as a standard strategy in patients with a high perioperative risk profile or a low likelihood of achieving cytoreduction to $\leq 1 \mathrm{~cm}$ of residual disease (5).

However, following an apparently effective NAC, it is common to discover during the surgery procedure that optimal resection is finally not possible $(6,8)$. Among multiple reasons for such finding, the current imagining tests lack of accuracy for predicting tumor response to treatments, due to the small sizes of peritoneal carcinomatosis lesions (9). As a consequence, there is a need for non-invasive tools able to predict the chances of resectability after NAC.

Some authors have developed predictive models based on clinical characteristics, computed tomography imaging, or CA-125 levels $(10,11)$. Most of these approaches present 
strong limitations, and none of them have been yet validated. Mathematical modeling of CA-125 kinetics during neoadjuvant chemotherapy may be a promising strategy. Indeed, this modern approach presents several advantages, such as low dependence on selected timepoints, longitudinal analysis of tumor marker kinetics, along with consideration of inter- and intra-individual variability (12). The reproducible predictive values of modeled kinetic parameters of other serum tumor markers, such as CA-125, prostatespecific antigen (PSA), human chorionic gonadotropin (hCG), alpha-fetoprotein (AFP) and circulating tumor cells (CTCs) have been reported in previous works (13-17). A modeled kinetic parameter related to CA-125 elimination, KELIM (modeled CA-125 elimination rate constant), was reported with a strong prognostic value regarding progression free survival in patients with recurrent ovarian cancer treated with carboplatin-based chemotherapy regimens in CALYPSO phase III trial (17). The prognostic value of KELIM was then validated in 3 independent phase III databases in patients treated with 1 st line chemotherapy $(13,14,16,17)$.

We hypothesize that mathematical modeling of CA-125 kinetics during NAC may help predict the chance of optimal resection and time to second-line chemotherapy in ovarian cancers patients. The aim of the present exploratory retrospective study was to investigate the prognostic value of modeled CA-125 kinetic parameters regarding surgery outcomes.

\section{Patients and Methods}

The primary objective of the study was to characterize CA-125 kinetics with a kinetic semi-mechanistic model. The secondary objective was to identify modeled kinetic parameters which might harbor predictive values regarding the chance of optimal cytoreductive surgery, and longer time to second-line chemotherapy.

The data of patients consecutively treated in a gynecology department for pathologically proven stage IIIc or IV FIGO ovarian cancers with NAC followed by IDS between 2006 and 2014 were collected. To build a semi-mechanistic model of CA-125 kinetics, we included patients with at least 1 abnormal CA-125 level (>35 IU/ml) measured within 8 days before the first chemotherapy cycle, and at least 3 CA-125 level determinations during NAC. We excluded all patients with unavailable CA-125 level data, or incomplete clinicopathological data. Age at diagnosis, tumor histology, chemotherapy type, number of cycles, cycles dates, CA-125 level monitoring, surgery date and outcomes (cytoreductive surgery: optimal cytoreduction or not), were collected. Surgical procedures were all performed by different skilled gynecology oncology surgeons, considered as experts in radical surgical procedures, with the intent to achieve optimal cytoreduction. Surgical indications were validated in multidisciplinary meetings. All tumors were considered resectable based on pre-operative imaging. Optimal cytoreductive surgery was defined according to the 2009 Gynecologic Oncology group (GOG) criteria (18), based on the size of residual tumor nodules, as it was the reference during this period. Surgery was considered optimal if the residual tumor nodules did not exceed $1 \mathrm{~cm}$ in maximum diameter. The procedure included at least total abdominal hysterectomy and bilateral salpingo-oophorectomy, supra-mesocolic omentectomy, pelvic and para-aortic lymph node dissection. The neoadjuvant chemotherapy regimens were determined by medical oncologists based on international recommendations.

Individual CA-125 data were analyzed using a population kinetic approach with a non-linear mixed effect model $(19,20)$, and were Log transformed. Basic details of population kinetic approach have been presented elsewhere (12). A semi-mechanistic model based on kinetic-pharmacodynamic (K-PD) approach was used to fit serum CA-125 values available before IDS (21). Indeed, K-PD models are commonly used in the absence of pharmacokinetic (PK) data for pharmacokinetic studies. As shown in Figure 1, treatment kinetic was described using a 2-virtual-compartment model, where A1 represents chemotherapy in the central compartment, A2 chemotherapy in the transit compartment and A3 the CA-125 rate. The inhibition of CA-125 production induced by treatment was expressed by an indirect effect model using an Emax relationship (22). $\mathrm{K}$ is the treatment kinetic rate constant (years ${ }^{-1}$ ); KPROD is the CA-125 basal tumor production rate (UI ml-1 per year); $\mathrm{E}_{50}$ is the concentration producing $50 \%$ of the maximum effect (arbitrary unit; AU); KELIM is the CA-125 elimination rate (years ${ }^{-1}$ ); and CA- $125_{0}$ is CA- 125 baseline determined by the model (UI ml-1).

$$
\begin{aligned}
& \frac{d \mathrm{~A} 1}{d \mathrm{t}}=-\mathrm{K} \times \mathrm{A} 1 \\
& \frac{d \mathrm{~A} 2}{d \mathrm{t}}=\mathrm{K} \times \mathrm{A} 1-\mathrm{K} \times \mathrm{A} 2 \\
& \frac{d \mathrm{~A} 3}{d \mathrm{t}}=\mathrm{KPROD} \times\left(1-\frac{\mathrm{A} 2}{\mathrm{E} 50+\mathrm{A} 2}\right)-\mathrm{KELIM} \times \mathrm{A} 3 \\
& \text { IC: } \mathrm{A} 1_{\mathrm{t} 0}=\mathrm{A} 2_{\mathrm{t} 0}=0 ; \mathrm{A} 3_{\mathrm{t} 0}=\mathrm{CA}-125_{0}
\end{aligned}
$$

To validate the best model, we assessed standard errors of estimated parameters, goodness-of-fit plots and distribution of the normalized prediction distribution errors (NPDE). In addition CA-125 decline profiles were simulated in 43,200 virtual patients (800 simulations) using the final individual parameters estimated from the best model to perform a visual predictive check (VPC, i.e., 10th and 90th percentiles of the observed CA-125 data values were compared to a $95 \%$ confidence interval $[\mathrm{CI}]$ of CA-125 titers from the 800 simulated replicates). We used VPC to assess the internal validity of the model. The predictive values of modeled kinetics parameters $\left(\mathrm{K}\right.$; KPROD; $\mathrm{E}_{50}$; KELIM; CA-125 ) categorized by their medians were tested regarding outcomes using univariate and multivariate analyses. Moreover, predictive CA-125 cut-offs previously reported in the literature were also investigated: CA125 value $\leq$ or $>75 \mathrm{IU} / \mathrm{ml}$ after the third cycle of chemotherapy (CA-125 $5_{\text {Post } \mathrm{C} 3}$ and CA-125 $5_{\text {Post C3MOD }}$ ); and CA125 value $\leq$ or $>20 \mathrm{IU} / \mathrm{ml}$ before IDS (CA-125 $5_{\text {Pre IDS }}$ and CA$125_{\text {PreIDSMOD }}(10,11)$. Multivariate logistic regressions were used to assess their predictive values regarding surgery outcomes (i.e. optimal cytoreduction: yes or no).

Kaplan-Meier curves and Log-rank tests were used to assess the predictive values of these parameters regarding time to second-line chemotherapy in patients with optimal cytoreduction using univariate analyses. All variables significant with $p \leq 0.3$ were included in the multivariate Cox model. A landmark time to second- 


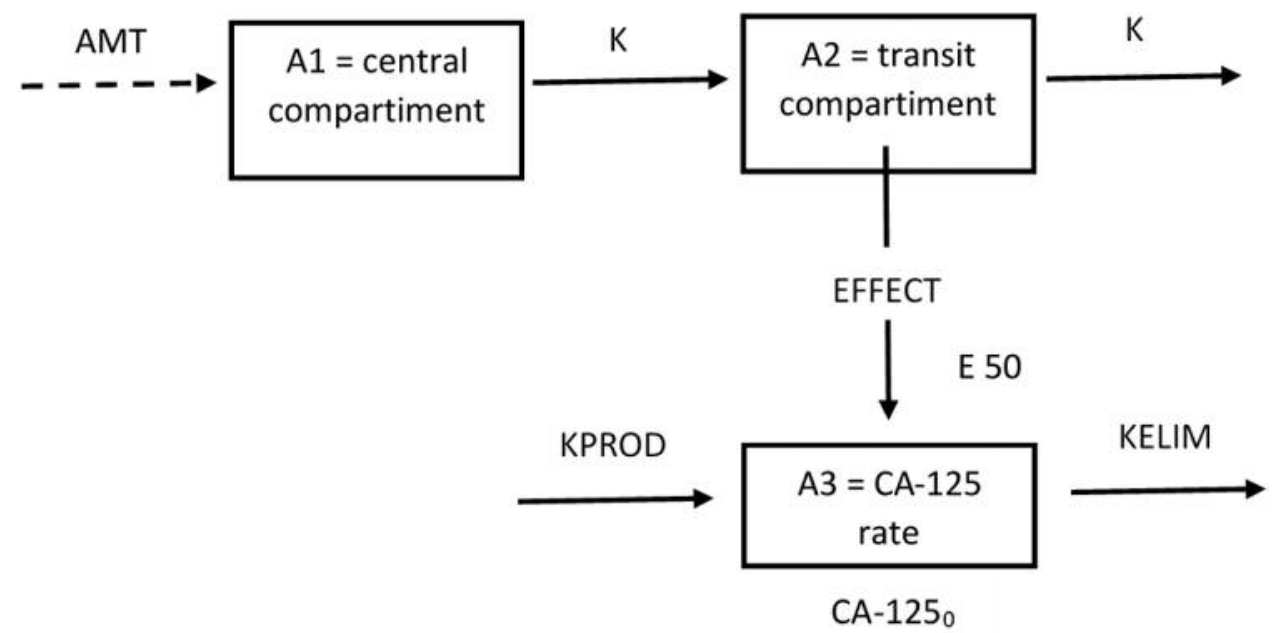

Figure 1. Description of the semi-mechanistic model. AMT: Administration treatment; A1: central compartment receiving chemotherapy dosing; K: treatment kinetics; A2: transit compartment to describe the treatment lag-time effect; EFFECT: production inhibition; $E_{50}$ : concentration producing 50\% of the maximum effect; KPROD: CA-125 tumor production rate; A3: CA-125 rate; KELIM: CA-125 elimination rate; CA-1250: CA-125 baseline determined by the model.

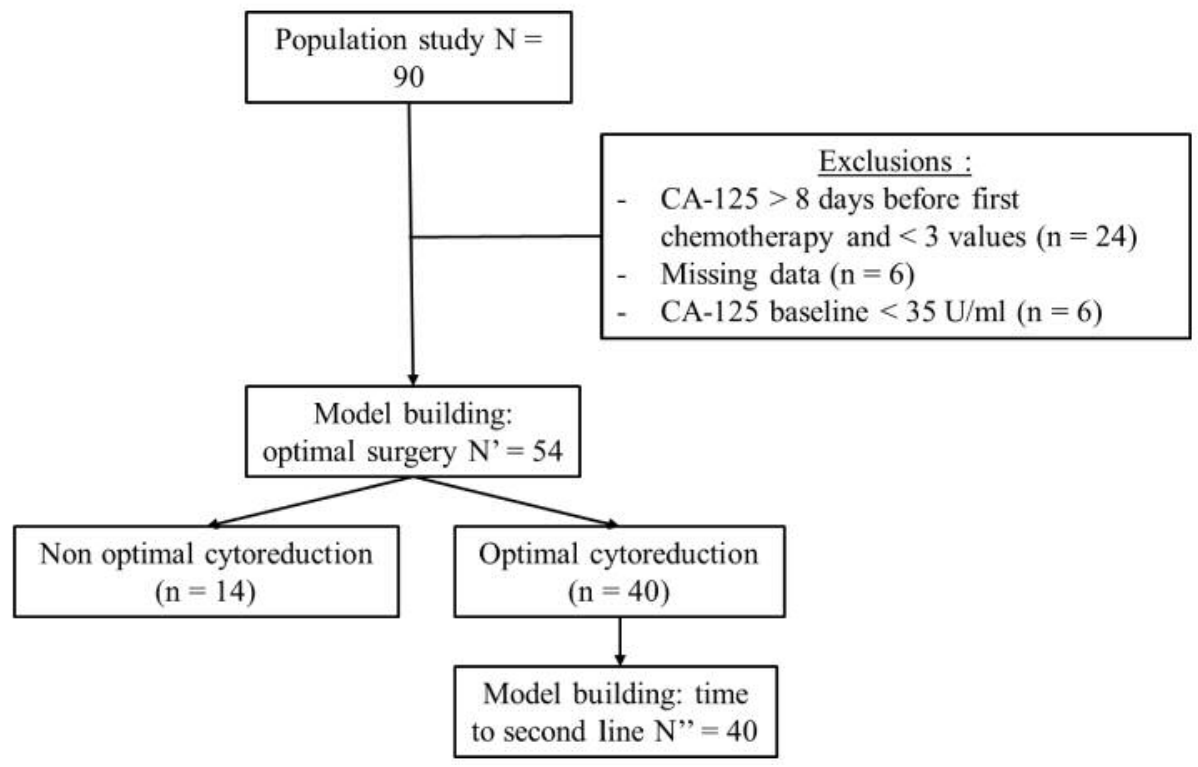

Figure 2. Selection of patients included in the present study.

line chemotherapy in the optimally cytoreduced population was used with landmark time point at IDS.

The NONNEM 7.3.0 software (ICON Development Solutions, Ellicott city, MD, USA) was used to fit CA-125 kinetics to the semi-mechanistic model using the SAEM method. Data handling, survival analyses and graphical representations were performed in R (C) 3.2.1 software. All tests were implemented using a two-sided 0.05 alpha risk.

\section{Results}

The data from 54 patients treated with NAC between 2006 and 2014 were collected and analyzed for modeling purpose (Figure 2). The median follow-up was 28.1 months (range $=9.0-117.5$ months). The patient clinical characteristics are summarized in Table I. Optimal IDS was achieved in 40 
Table I. Patient clinical characteristics.

\begin{tabular}{lcc}
\hline Characteristic & $\begin{array}{c}\text { Optimal IDS } \\
(\mathrm{n}=40)\end{array}$ & $\begin{array}{c}\text { Non optimal IDS } \\
(\mathrm{n}=14)\end{array}$ \\
\hline Age (years) & 63 & 67 \\
& {$[36-86]$} & {$[43-85]$} \\
FIGO stage & $33(82.5 \%)$ & $10(71.4 \%)$ \\
IIIc & $7(17.5 \%)$ & $4(28.6 \%)$ \\
IV & & \\
Histology & $28(70.0 \%)$ & $9(64.3 \%)$ \\
Serous & $12(30.0 \%)$ & $5(35.7 \%)$ \\
Others & 1,283 & 3,370 \\
Baseline CA-125 (U.ml-1) & {$[37-5,966]$} & {$[73-17,621]$} \\
Cycles of NAC & 5.0 & 5.4 \\
& {$[3.0-7.0]$} & {$[3.0-7.0]$} \\
NAC type & & $13(92.9 \%)$ \\
Taxane and platinum & $40(100 \%)$ & 0 \\
CHIVA & $5(12.5 \%)$ & $1(7.1 \%)$ \\
Platinum based & 0 & \\
\hline
\end{tabular}

IDS, Interval debulking surgery; NAC, neo adjuvant chemotherapy.

patients $(74.1 \%)$. However 14 patients were not optimally cytoreduced $(25.9 \%)$ because 5 had massive diffuse peritoneal carcinomatosis, 4 had miliary carcinomatosis, 3 had iliac fossa or parametrium deep lymph node involvement, 1 had pleural carcinomatosis and 1 had hepatic pedicle infiltration. Mean age was 63 years for optimal IDS, and 67 years for non-optimal IDS. Thirty three $(82.5 \%)$ and 10 patients $(71.4 \%)$ had stage IIIc diseases in optimal and in non-optimal surgery groups, respectively. The median CA-125 levels before the first cycle of chemotherapy was $1,283 \mathrm{IU} / \mathrm{ml}$ for optimal IDS (range=37-5,966 IU $/ \mathrm{ml}$ ) against $3,370 \mathrm{IU} / \mathrm{ml}$ for non-optimal IDS (range=73-17,621 IU/ml). All patients who underwent optimal surgery had received taxane and platinum-based NAC. Five optimally cytoreduced patients had been in CHIVA trial assessing the efficacy of an anti-angiogenic drug (nintedanib) in addition to first line preoperative chemotherapy. The median number of neoadjuvant cycles was 5.0 (range=3-7) and 5.4 (range=3-7) in optimal and non-optimal IDS groups respectively.

Typical parameters and between subject variability (BSV) estimated from the semi-mechanistic model for CA-125 kinetics are presented in Table II. Relative standard errors (RSE) of typical parameters were all less than $40 \%$, excepted for KPROD. The goodness-of-fit plots demonstrated that CA125 kinetics were properly fitted by the model before IDS. Observations versus individual predictions were close to the identity line (Figure 3a). NPDE did not deviate from a standard normal distribution and suggested that the model and population parameters distributions were correct (Figure 3b). VPC showed that most of the CA-125 values were included within the $90 \%$ confidence interval boundaries of simulated CA-125 predictions (Figure $3 \mathrm{c}$ of Figure 3), thereby suggesting the good predictive performance of the model.

Using univariate logistic analysis, CA-125 elimination rate parameter KELIM exhibited a strong predictive value regarding optimal IRS (Table III) (odds ratio $(\mathrm{OR})=0.18$, $95 \%$ confidence interval [0.04 to 0.69 ]; $p=0.02$ ). The other modeled kinetic parameters were not significant, including treatment kinetic rate constant $\mathrm{K}(p=0.21), \mathrm{CA}-125$ tumor production rate KPROD $(p=0.07)$, concentration producing $50 \%$ of the maximum effect $\mathrm{E}_{50}(p=0.53)$ and CA-125 baseline CA-125 $(p=0.21)$. Among covariates based on CA125 thresholds, only CA- $125_{\text {Post } \mathrm{C} 3}$, was found significant $(\mathrm{OR}=4.15 ; 95 \% \mathrm{C}=1.15-15.96 ; p=0.03)$. Using multivariate analysis performed including parameters with $p \leq 30 \%$ significance in univariate analyses (KELIM, KPROD, CA$125_{\text {Post C3 }}$ ), KELIM was the only independent parameter regarding the likelihood of optimal cytoreduction $(\mathrm{OR}=0.18$; 95\% CI=0.04-0.69; $p=0.02$ ).

The data of 40 patients who underwent optimal cytoreduction surgery were analyzed. Using Kaplan-Meier curves, 2 modeled kinetic parameters had strong predictive values: $\mathrm{E}_{50}$ (11.7 months if $\mathrm{E}_{50}$ is < median vs. 25.0 months if $\mathrm{E}_{50} \geq$ median, $p=0.015$ ) (Figure 4 and Table III); baseline CA-125 (29.5 months if CA-1250 < median vs. 13.2 months if CA- $125_{0} \geq$ median, $p=0.03$ ). In a multivariate Cox regression model including these significant prognostic factors, $\mathrm{E}_{50}$ was the only significant covariate $(\mathrm{HR}=0.38$; $95 \% \mathrm{CI}=0.173-0.854 ; p=0.019$ ).

\section{Discussion}

The residual tumor size after cytoreductive surgery is one of the most important prognostic factors regarding survival in EOC (5-7). The GOG defined optimal surgery as residual tumor nodules measuring $1 \mathrm{~cm}$ or less in maximum diameter (18). In our population, $74.1 \%$ of patients who underwent IDS had residual nodules tumors $<1 \mathrm{~cm}$ after surgery, with the intent to achieve optimal cytoreduction. Data from clinical trials subsequently suggested that resection to microscopic tumor burden was associated with improved survival time (23) and gynecology oncologists now consider that the aim of cytoreductive surgery should ideally be no residual disease.

Although pre-operative prediction of optimal surgery could guide treatment decisions, few studies reported approaches able to forecast the amount of residual disease after cytoreductive surgery and NAC. Some authors have attempted to use computed tomography imaging to predict the amount of residual tumor after cytoreductive surgery. However, the radiologic models had poor reproducibility for predicting any residual disease after surgery, due to the small and heterogeneous size of peritoneal lesions (9). Other authors 
Table II. Parameters of the model.

\begin{tabular}{|c|c|c|c|c|c|}
\hline Parameter (unit) & Estimate & RSE $(\%)$ & $\begin{array}{c}\text { BSV } \\
\text { (\% coefficient of variation) }\end{array}$ & $\begin{array}{l}\text { RSE BSV } \\
(\%)\end{array}$ & $\begin{array}{l}\text { Shrinkage } \\
\qquad \%)\end{array}$ \\
\hline $\mathrm{K}\left(\right.$ years $\left.^{-1}\right)$ & 0.0203 & 15.8 & 56.7 & 28.3 & 16.2 \\
\hline KPROD (U.ml $l^{-1}$ per year) & 226 & 44.7 & 129.6 & 43.2 & 32 \\
\hline $\mathrm{E}_{50}(\mathrm{AU})$ & 10.6 & 38.5 & 95.3 & 40.9 & 15.3 \\
\hline KELIM (years ${ }^{-1}$ ) & 18.3 & 18.5 & 72.8 & 25.1 & 17.8 \\
\hline $\mathrm{CA}-125_{0}\left(\mathrm{U} \cdot \mathrm{ml}^{-1}\right)$ & 678 & 24.8 & 146.6 & 16.6 & 3.97 \\
\hline
\end{tabular}

RSE, Relative standard error; BSV, Between Subject Variability; K, treatment kinetics; KPROD, CA-125 tumor production rate; $\mathrm{E}_{50}$, concentration producing $50 \%$ of the maximum effect; KELIM, CA-125 elimination rate; CA-1250, CA-125 baseline determined by the model.

Table III. Results of univariate analyses regarding predictive values of modeled kinetic parameters: likelihood of optimal resection and time to second-line chemotherapy in optimally cytoreduced population.

\begin{tabular}{|c|c|c|c|c|c|}
\hline \multirow[t]{2}{*}{ Variables } & \multicolumn{2}{|c|}{$\begin{array}{l}\text { Likelihood of optimal } \\
\text { resection }\end{array}$} & \multicolumn{3}{|c|}{$\begin{array}{l}\text { Time to second-line chemotherapy in } \\
\text { optimally cytoreduced population }\end{array}$} \\
\hline & OR $[95 \% \mathrm{CI}]$ & $p$-Value & Median & Kaplan-Meier curves (Months) & $p$-Value \\
\hline $\mathrm{K}\left(\right.$ years $\left.^{-1}\right)$ & $0.45[0.12-1.56]$ & 0.21 & $\begin{array}{l}<0.201 \\
\geq 0.201\end{array}$ & $\begin{array}{l}14.2 \\
23.5\end{array}$ & 0.38 \\
\hline KPROD $\left(\mathrm{U} \cdot \mathrm{ml}^{-1}\right.$ per year $)$ & $0.3[0.07-1.05]$ & 0.07 & $\begin{array}{l}<264.175 \\
\geq 264.175\end{array}$ & $\begin{array}{l}18.7 \\
11.7\end{array}$ & 0.06 \\
\hline $\mathrm{E}_{50}(\mathrm{AU})$ & $0.68[0.19-2.30]$ & 0.53 & $\begin{array}{l}<0.121 \\
\geq 0.121\end{array}$ & $\begin{array}{l}11.7 \\
25\end{array}$ & 0.016 \\
\hline KELIM (years ${ }^{-1}$ ) & $0.18[0.04-0.69]$ & 0.02 & $\begin{array}{l}<18.68 \\
\geq 18.68\end{array}$ & $\begin{array}{l}14.2 \\
23.5\end{array}$ & 0.38 \\
\hline $\mathrm{CA}-125_{0}\left(\mathrm{U} \cdot \mathrm{ml}^{-1}\right)$ & $2.2[0.64-8.28]$ & 0.21 & $\begin{array}{l}<619 \\
\geq 619\end{array}$ & $\begin{array}{l}29.5 \\
13.2\end{array}$ & 0.03 \\
\hline CA-125 Post C3 $\left(\mathrm{U} \cdot \mathrm{ml}^{-1}\right)$ & $4.15[1.15-15.96]$ & 0.03 & $\begin{array}{l}\leq 75 \\
>75\end{array}$ & $\begin{array}{l}19.6 \\
14.2\end{array}$ & 0.264 \\
\hline CA-125 Post C3MOD $\left(\mathrm{U} \cdot \mathrm{ml}^{-1}\right)$ & $2.77[0.80-10.0]$ & 0.10 & $\begin{array}{l}\leq 75 \\
>75\end{array}$ & $\begin{array}{l}21.6 \\
13.2\end{array}$ & 0.08 \\
\hline CA-125 Pre IDS $\left(\mathrm{U} \cdot \mathrm{ml}^{-1}\right)$ & $1.8[0.53-6.75]$ & 0.35 & $\begin{array}{l}\leq 20 \\
>20\end{array}$ & $\begin{array}{l}19.6 \\
14.2\end{array}$ & 0.124 \\
\hline CA-125 Pre IDSMOD $\left(\mathrm{U} \cdot \mathrm{ml}^{-1}\right)$ & $2.33[0.67-8.32]$ & 0.18 & $\begin{array}{l}\leq 20 \\
>20\end{array}$ & $\begin{array}{l}19.6 \\
14.2\end{array}$ & 0.43 \\
\hline
\end{tabular}

$\mathrm{K}$, Treatment kinetics; KPROD, CA-125 tumor production rate; $\mathrm{E}_{50}$, concentration producing $50 \%$ of the maximum effect; KELIM, CA-125 elimination rate; CA- $125_{0}$, CA-125 baseline determined by the model; CA- $125_{\text {Post }}$, , CA125 value $\leq$ or $>75 \mathrm{U} / \mathrm{ml}$ after the third cycle of chemotherapy; CA-125 $5_{\text {Post C3MOD }}$, CA125 value $\leq$ or $>75 \mathrm{U} / \mathrm{ml}$ after the third cycle of chemotherapy determined by the model; CA-125 Pre IDS, CA125 value $\leq$ or $>20 \mathrm{U} / \mathrm{ml}$ before interval debulking surgery; CA-125 Pre IDSMOD , CA125 value $\leq$ or $>20 \mathrm{U} / \mathrm{ml}$ before interval debulking surgery determined by the model.

tried to define CA-125 thresholds to predict optimal cytoreduction. Furukawa et al. reported a $20 \mathrm{IU} / \mathrm{ml} \mathrm{CA-125}$ as a specific and sensitive cut-off before IDS (sensitivity $74.4 \%$, and specificity $82.1 \%$ ) (10). Pelissier et al. determined that a CA-125 value of less than $75 \mathrm{IU} / \mathrm{ml}$ after 3 cycles of chemotherapy was an independent predictor of complete IDS (sensitivity: 52\% [40\%-63\%], specificity: 68\% [62\%-74\%]; $p=0.02$ ) in a retrospective study with 148 patients (11). These covariates were tested in our study, and only a CA-125 value of less than $75 \mathrm{IU} / \mathrm{ml}$ after 3 cycles of chemotherapy was significant using univariate analysis $(\mathrm{OR}=4.15$; $95 \% \mathrm{C}=1.15$ 15.96; $p=0.03)$. The limited reproducibility of CA-125 thresholds is probably due to the fact that they were arbitrarily set by authors after comparing the predictive values of different cut-offs. These simple static approaches rely on one time-point, without consideration of intra and inter-individual variabilities related to tumor biomarker assays (12). None of them have been shown to be reproducible yet. 
a

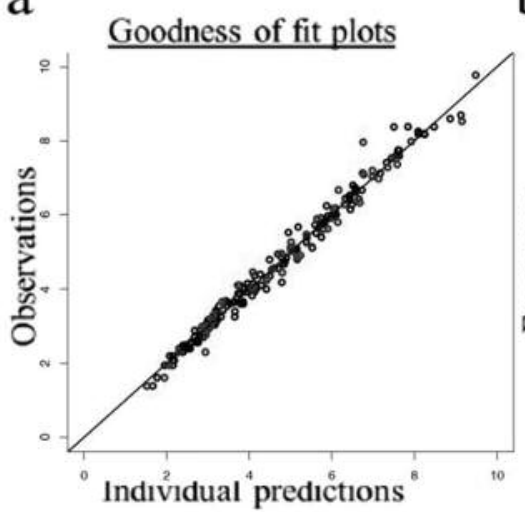

b

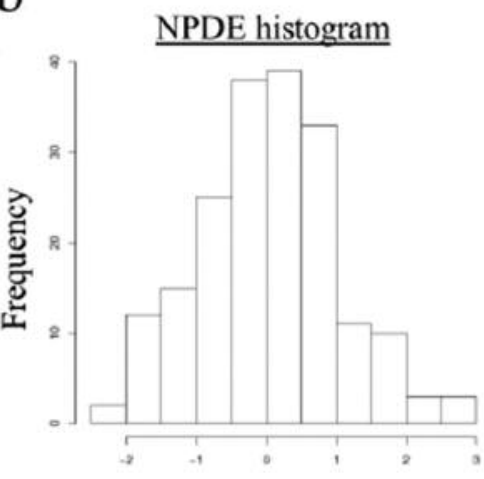

C

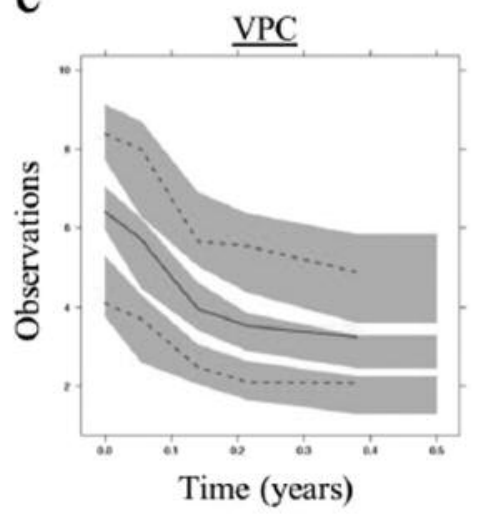

Figure 3. Model validation. a. Goodness of fit plots. Observed CA-125 values vs individual predicted CA-125 values. Black line: identity line, Black circles: Optimal Resection, Blue circles: Sub-Optimal Resection. b. Normalized prediction distribution errors distribution (NPDE). c. Visual predictive check (VPC). Red lines represent the median (solid line), and the 10th and 90th percentiles (dashed lines) of the observed CA-125 data. Blue area represent the $95 \%$ confidence intervals of simulations.

Integration of several CA125 measurements in mathematical models reduces the effects of intra-individual variability by assessing the equations describing the whole decline curves, on an individual basis. In previous studies involving recurrent ovarian cancer patients, KELIM, a kinetic parameter describing CA125 elimination rate, was a strong independent predictive value of tumor lesion size changes (13), progression-free survival (17) and overall survival in independent phase III trial databases (24). Consistently, we analyzed the roles of modeled CA-125 kinetic parameters as potential predictors of optimal cytoreduction after NAC in the present study (17). KELIM, already reported previously, was found to be an independent predictive factor of optimal cytoreduction. Moreover, another modeled kinetic parameter $\mathrm{E}_{50}$ was a strong predictive factor of time to second-line chemotherapy in optimally cytoreduced patients. $\mathrm{E}_{50}$ represents the concentration producing $50 \%$ of the maximum effect of chemotherapy. As a consequence, it somehow represents the strength of chemotherapy, and suggests that initial chemotherapy efficiency might explain a part of the recurrence risk in such patients.

There are some limitations in our study. It is a retrospective study with a limited number of patients treated in a single institute. IDS and chemotherapy were validated in multidisciplinary meetings based on international recommendations that evolved during the study period. The PCI and Fagotti modified score are now routinely used to describe the extent of peritoneal spread, and the resectability of ovarian cancer (25-27). It was not the case before 2010, thereby explaining why data about peritoneal cancer index (PCI) could not be extracted for the present work. In the present real-life study, cytoreductive surgery was usually performed after 3 cycles of chemotherapy, as assessed in the CHORUS trial (8). However, patients were sometimes

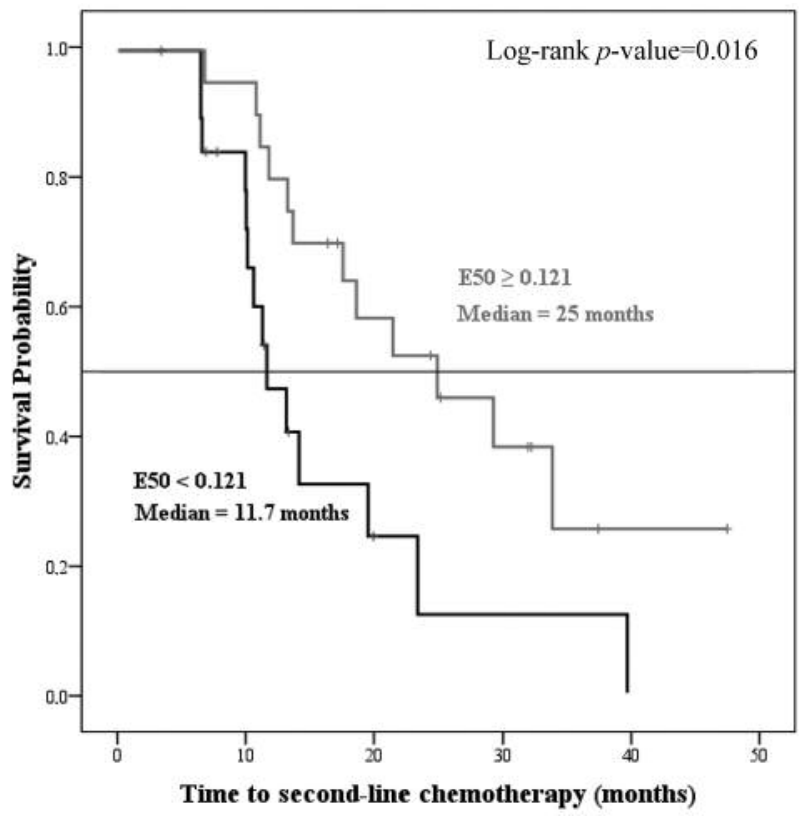

Figure 4. Kaplan-Meier curves time to second-line chemotherapy in optimally cytoreduced population; $E_{50}$ : concentration producing $50 \%$ of the maximum effect.

operated after 6 cycles, when tumor response was insufficient for optimal surgery, thereby inducing some heterogeneity in the cohort data.

Despite these limitations, the outcomes of the present exploratory study suggest that modeled kinetic parameters may help identify patients who might have optimal cytoreduction after neoadjuvant chemotherapy, and shorter 
time to second-line chemotherapy in optimally cytoreduced patients. Additional confirmatory studies are needed, and we have planned to i) assess the predictive value of KELIM and $\mathrm{E}_{50}$ in the CHIVA randomized phase II trial dababase, and ii) to perform a prospective study to validate the value of these modeled kinetic parameters.

\section{Acknowledgements}

The Authors thank the physicians and staffs who were involved in patient management and who contributed to generate the data.

\section{References}

1 Ferlay J, Soerjomataram I, Dikshit R, Eser S, Mathers C, Rebelo M, Parkin DM, Forman D and Bray F: Cancer incidence and mortality worldwide: sources, methods and major patterns in GLOBOCAN 2012. Int J Cancer 136: E359-386, 2014.

2 Weidle UH, Birzele F, Kollmorgen $G$ and Rueger R: Mechanisms and targets involved in dissemination of ovarian cancer. Cancer Genomics Proteomics 13: 407-423, 2016.

3 Maringe C, Walters S, Butler J, Coleman MP, Hacker N, Hanna L, Mosgaard BJ, Nordin A, Rosen B, Engholm G, Gjerstorff ML, Hatcher J, Johannesen TB, McGahan CE, Meechan D, Middleton R, Tracey E, Turner D, Richards MA, Rachet B and ICBP Module 1 Working Group: Stage at diagnosis and ovarian cancer survival: evidence from the International Cancer Benchmarking Partnership. Gynecol Oncol 127: 75-82, 2012.

4 Wright AA, Bohlke K, Armstrong DK, Bookman MA, Cliby WA, Coleman R.L, Dizon DS, Kash JJ, Meyer LA, Moore KN, Olawaiye AB, Oldham J, Salani R, Sparacio D, Tew WP, Vergote I and Edelson MI: Neoadjuvant chemotherapy for newly diagnosed, advanced ovarian cancer: Society of Gynecologic Oncology and American Society of Clinical Oncology Clinical Practice Guideline. J Clin Oncol 28: 3460-3473, 2016.

5 Aletti GD, Dowdy SC, Gostout BS, Jones MB, Stanhope CR, Wilson TO, Podratz KC and Cliby WA: Aggressive surgical effort and improved survival in advanced-stage ovarian cancer. Obstet Gynecol 107: 77-85, 2006.

6 Vergote I, Tropé CG, Amant F, Kristensen GB, Ehlen T, Johnson N, Verheijen RHM, Van der Burg MEL, Lacave AJ, Benedetti Panici P, Kenter GG, Casado A, Mendiola C, Coens C, Verleye L, Stuart GCE, Pecorelli S and Reed NS: Neoadjuvant Chemotherapy chemotherapy or Primary primary Surgery surgery in Stage stage IIIC or IV Ovarian ovarian Cancercancer. N Engl J Med 363: 943-953, 2010.

7 Horowitz NS, Miller A, Rungruang B, Richard SD, Rodriguez N, Bookman MA, Hamilton CA, Krivak TC and Maxwell GL: Does Aggressive aggressive Surgery surgery Improve improve Outcomesoutcomes? Interaction Between between Preoperative preoperative Disease disease Burden burden and Complex complex Surgery surgery in Patients patients With with Advancedadvanced-Stage stage Ovarian ovarian Cancercancer. J Clin Oncol 33: 937-943, 2015.

8 Kehoe S, Hook J, Nankivell M, Jayson GC, Kitchener H, Lopes T, Luesley D , Perren T, Bannoo S, Mascarenhas M, Dobbs S, Essapen S, Twigg J, Herod J, Mc Cluggage G, Parmar M and Swart AM: Primary chemotherapy versus primary surgery for newly diagnosed advanced ovarian cancer (CHORUS): an openlabel, randomised, controlled, non-inferiority trial. Lancet 386 : 249-257, 2015.

9 Rutten MJ, van de Vrie R, Bruining A, Spijkerboer AM, Mol BW, Kenter GG and Buist MR: Predicting surgical outcome in patients with International Federation of Gynecology and Obstetrics stage III or IV ovarian cancer using computed tomography: a systematic review of prediction models. Int J Gynecol Cancer 25: 407-415, 2015.

10 Furukawa N, Sasaki Y, Shigemitsu A, Akasaka J, Kanayama S, Kawaguchi R and Kobayashi H: CA-125 cut-off value as a predictor for complete interval debulking surgery after neoadjuvant chemotherapy in patients with advanced ovarian cancer. Gynecol Oncol 24: 141-145, 2013.

11 Pelissier A, Bonneau C, Chéreau E, La Motte Rouge de T, Fourchotte V, Daraï E and Rouzier R: CA125 kinetic parameters predict optimal cytoreduction in patients with advanced epithelial ovarian cancer treated with neoadjuvant chemotherapy. Gynecol Oncol 135: 542-546, 2014.

12 Almufti R, Wilbaux M, Oza A, Hénin E, Freyer G, Tod M, Colomban O and You B: A critical review of the analytical approaches for circulating tumor biomarker kinetics during treatment. Annals of Oncology 25: 41-56, 2014.

13 Wilbaux M, Hénin E, Oza A, Colomban O, Pujade-Lauraine E, Freyer G, Tod M and You B: Prediction of tumour response induced by chemotherapy using modelling of CA-125 kinetics in recurrent ovarian cancer patients. Br J Cancer 110: 15171524, 2014.

14 You B, Harvey R, Hénin E, Mitchell H, Golfier F, Savage PM, Tod M, Wilbaux M, Freyer G and Seckl MJ: Early prediction of treatment resistance in low-risk gestational trophoblastic neoplasia using population kinetic modelling of hCG measurements. Br J Cancer 108: 1810-1816, 2013.

15 Wilbaux M, Hénin E, Oza A, Colomban O, Pujade-Lauraine E, Freyer G, Tod M and You B: Dynamic modeling in ovarian cancer: an original approach linking early changes in modeled longitudinal CA-125 kinetics and survival to help decisions in early drug development. Gynecol Oncol 133: 460-466, 2014.

16 You B, Colomban O, Tod M, Ray Coquard I, Lortholary A, Hardy-Bessard AC, Du Bois A, Huober J, Meier W, Kurzeder C and Pfisterer J: The predictive value of the CA-125 modeled kinetic parameter KELIM is validated in 3 independent datasets (AGO-OVAR 7 \& 9; ICON 7 AGO/GINECO/GCIG trials). Ann Oncol 27: 296-312, 2016.

17 You B, Colomban O, Heywood M, Lee C, Davy M, Reed N, Pignata S, Varsellona N, Emons G, Rehman K, Dahl Steffensen K, Reinthaller A, Pujade-Lauraine E and Oza A: The strong prognostic value of KELIM, a model-based parameter from CA 125 kinetics in ovarian cancer: Data from CALYPSO trial (a GINECO-GCIG study). Gynecol Oncol 130: 289-294, 2013.

18 Whitney CW and Spirtos N: Gynecologic Oncology Group Surgical Procedures Manual. Philadelphia: Gynecologic Oncology Group; 2009.

19 Sheiner LB: The population approach to pharmacokinetic data analysis: rationale and standard data analysis methods. Drug Metab Rev 15: 153-171, 1984.

20 Davidian M and Giltinan DM: Nonlinear models for repeated measurement data: An overview and update. J Agric Biol Environ StatJournal of Agricultural, Biological, and Environmental Statistics 8: 387-419, 2003. 
21 Jacqmin P, Snoeck E, Van Schaick EA, Gieschke R, Pillai P, Steimer J-L and Girard P: Modelling response time profiles in the absence of drug concentrations: definition and performance evaluation of the K-PD model. J Pharmacokinet Pharmacodyn 34: 57-85, 2006.

22 Sharma A and Jusko WJ: Characteristics of indirect pharmacodynamic models and applications to clinical drug responses. Br J Clin Pharmacol 45: 229-239, 1998.

23 Chang S-J, Hodeib M, Chang J and Bristow RE: Survival impact of complete cytoreduction to no gross residual disease for advanced-stage ovarian cancer: a meta-analysis. Gynecol Oncol 130: 493-498, 2013.

24 You B, Colomban O, Freyer G, Leary A, Ray-Coquard IL, Lortholary A, Hardy Bessard AC, Pfisterer J, Du Bois A, Kurzeder C, Burges A and Tod M: Two prognostic populations of ovarian cancer patients defined by CA125 modeled kinetic parameter KELIM (AGO-OVAR 7 \& 9; ICON 7 AGO/ GINECO/MRC CTU/GCIG trials). J Clin Oncol 35: abstr 5554, 2017 (suppl; abstr 5554).
25 Brun J-L, Rouzier R, Uzan S and Daraï E: External validation of a laparoscopic-based score to evaluate resectability of advanced ovarian cancers: clues for a simplified score. Gynecol Oncol 110: 354-359, 2008.

26 Tentes AAK, Tripsiannis G, Markakidis SK, Karanikiotis CN, Tzegas G, Georgiadis G and Avgidou K: Peritoneal cancer index: a prognostic indicator of survival in advanced ovarian cancer. Eur J Surg Oncol 29: 69-73, 2003.

27 Chéreau E, Ballester M, Selle F, Cortez A, Daraï E and Rouzier $\mathrm{R}$ : Comparison of peritoneal carcinomatosis scoring methods in predicting resectability and prognosis in advanced ovarian cancer. Am J Obstet Gynecol 202: 178.e1-178.e10, 2010.

Received August 31, 2017

Revised October 18, 2017

Accepted October 25, 2017 